\title{
Analytically approximate solution to the VLE problem with the SRK equation of state
}

\author{
Hongqin Liu ${ }^{1}$ \\ ${ }^{1}$ Shared Services Canada
}

October 30,2020

\begin{abstract}
In vapor liquid equilibrium (VLE) calculations with a cubic equation of state (EoS), exact solution has to be carried out numerically with an iterative approach [1,2]. This causes significant wastes of repetitive efforts and computing resources. Based on a recent study [3] on the van der Waals EoS [4,5], here we propose a procedure for analytically approximate solutions to the VLE calculation with the Soave-Redlich-Kwong (SRK) EoS [6] for the entire coexistence curve. This procedure can be applied to any cubic EoS. A simple databank can be built containing only the coefficients of a newly defined function and other thermodynamic properties will be obtained with analytical forms. For each system there is only a one-time effort. We also show that for exact solutions, the VLE problem with any cubic EoS can be reduced to solving a transcendental equation with one unknown, which can significantly simplify the methods currently employed [2,7].
\end{abstract}

\section{Hosted file}

analytical solution main text.pdf available at https://authorea.com/users/371423/articles/ 489772-analytically-approximate-solution-to-the-vle-problem-with-the-srk-equation-ofstate 

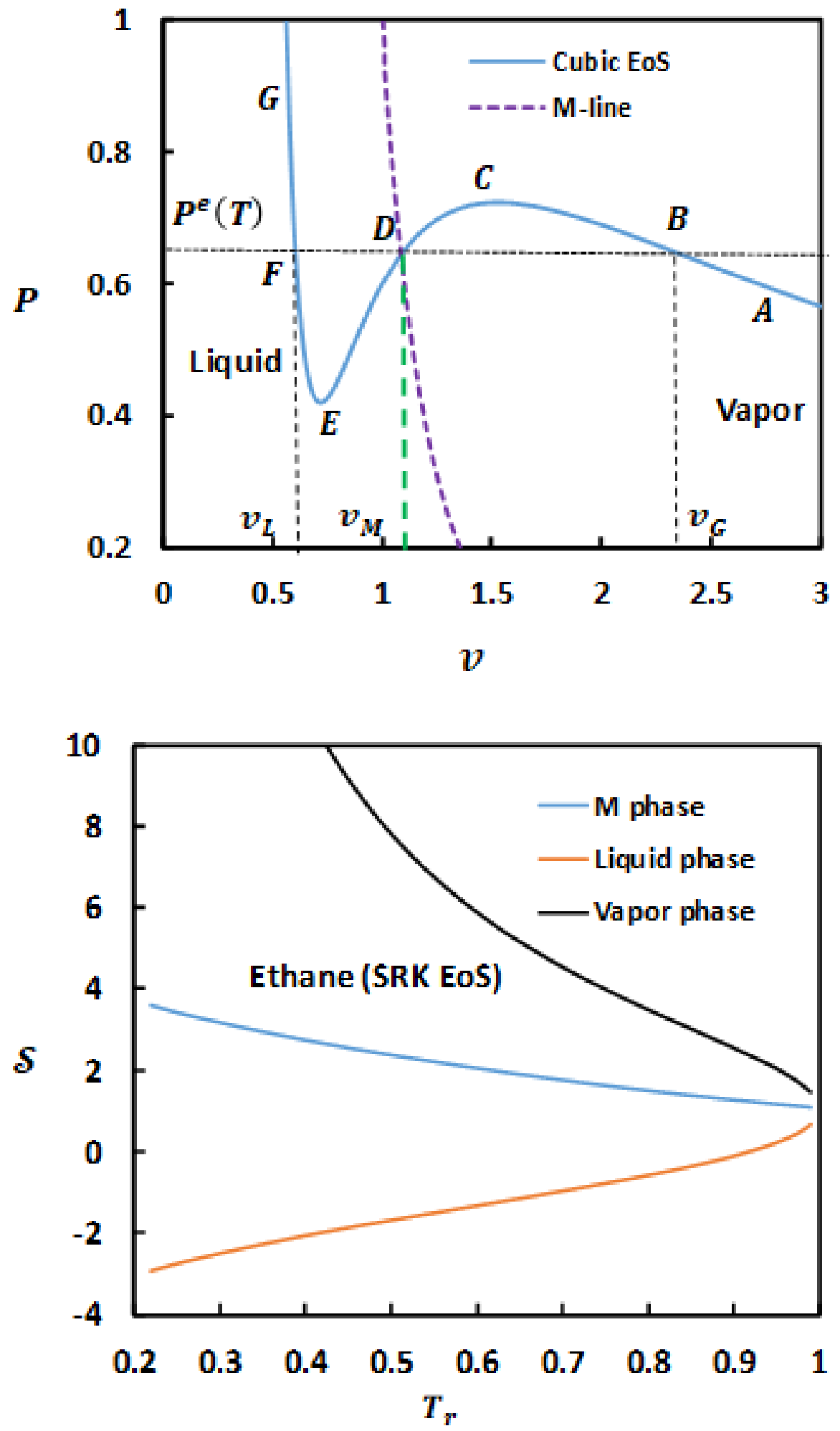

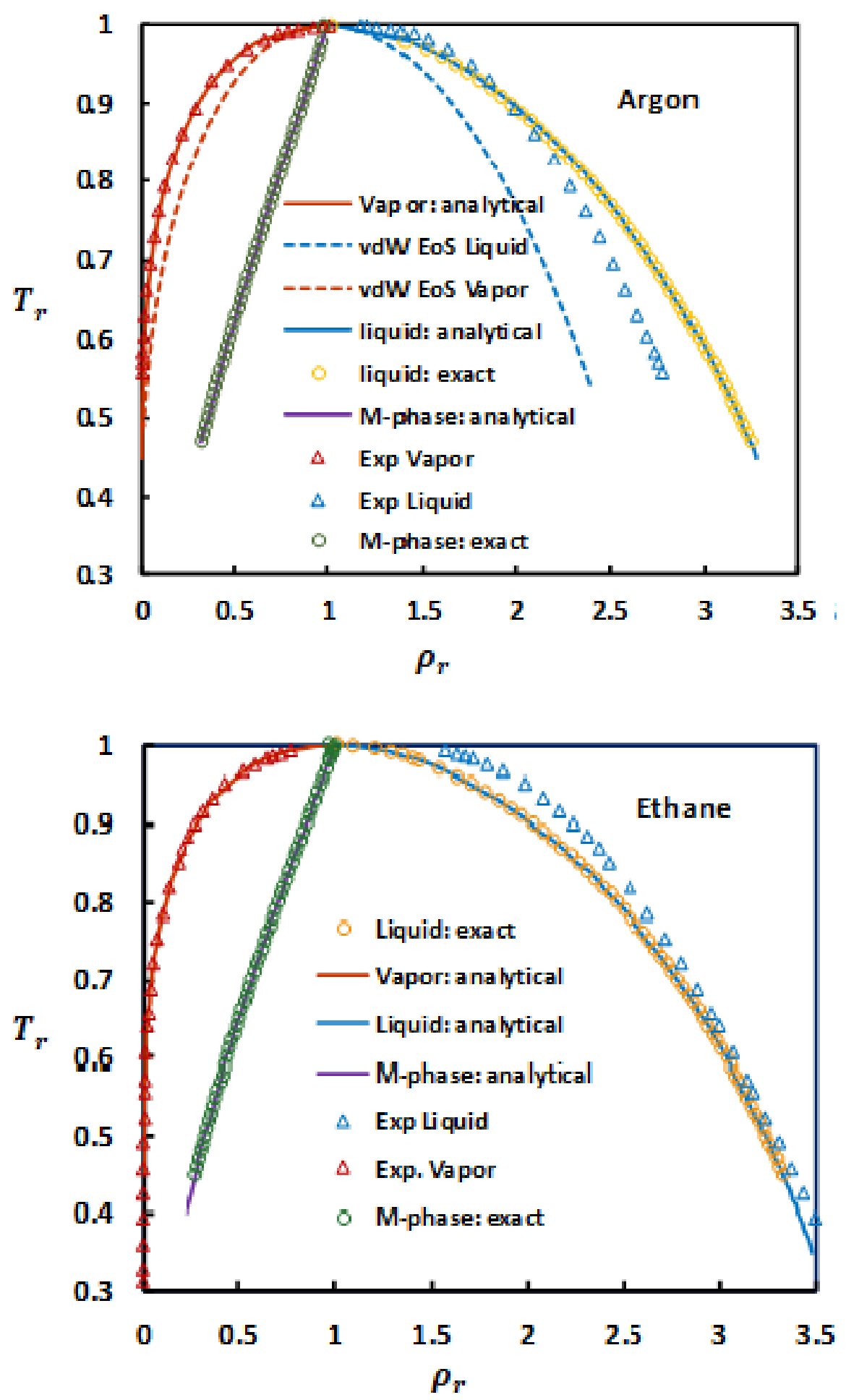

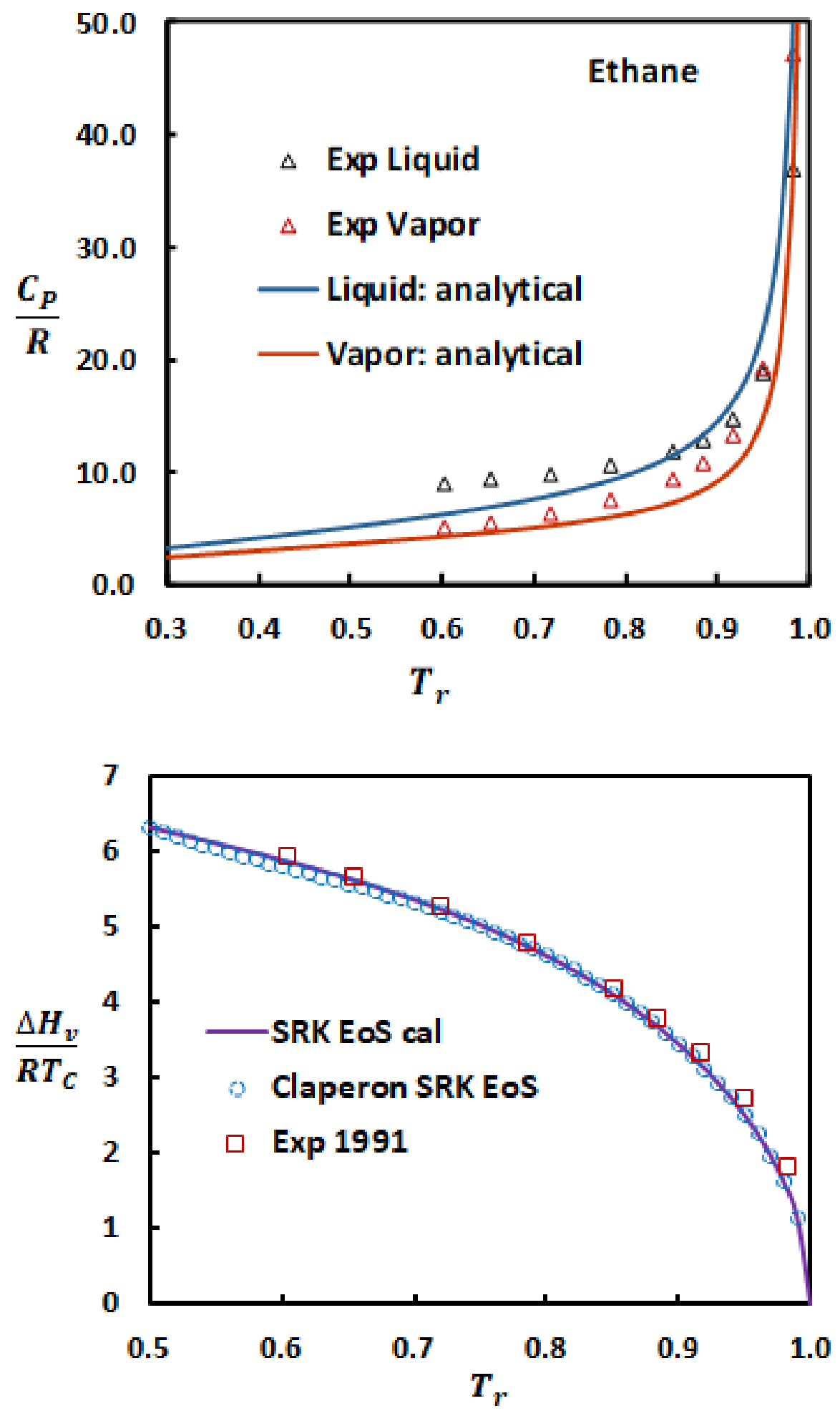


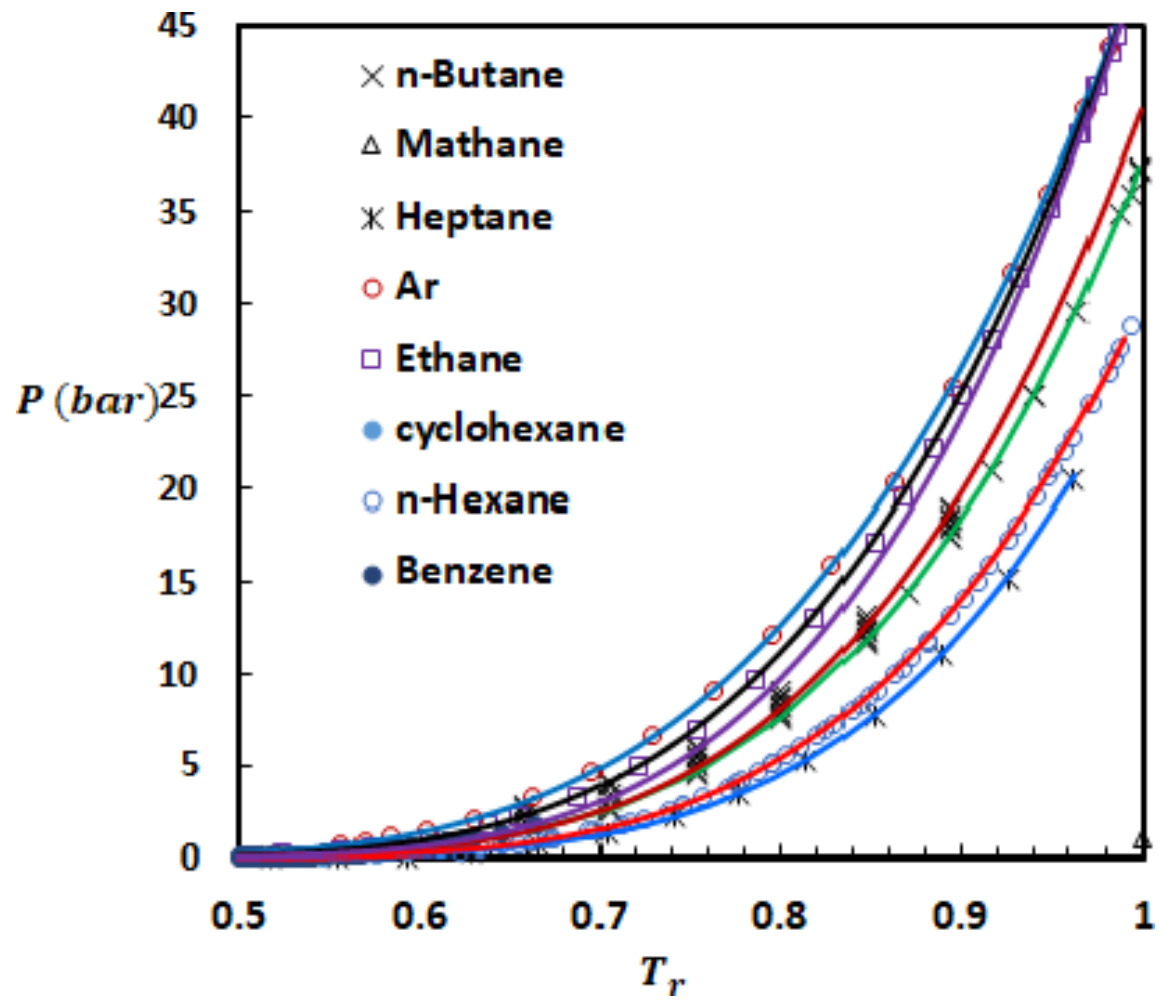

Hosted file

Table 1.pdf available at https://authorea.com/users/371423/articles/489772-analyticallyapproximate-solution-to-the-vle-problem-with-the-srk-equation-of-state

Hosted file

Table 2.pdf available at https://authorea.com/users/371423/articles/489772-analyticallyapproximate-solution-to-the-vle-problem-with-the-srk-equation-of-state

Hosted file

Table 3.pdf available at https://authorea.com/users/371423/articles/489772-analyticallyapproximate-solution-to-the-vle-problem-with-the-srk-equation-of-state 